\title{
Alavancando pesquisa, desenvolvimento e inovação no setor de autopeças: análise e propostas a partir de survey e estudo qualitativo focado
}

\author{
Mario Sergio Salerno ${ }^{a, *}$, Zil Miranda ${ }^{b}$, Fernando Yutaka Kamisakic, Geovani Maluta ${ }^{\mathrm{d}}$ \\ a,**msalerno@usp.br, USP, Brasil \\ bzil@usp.br, USP, Brasil \\ cfernando.kamisaki@gmail.com, USP, Brasil \\ ${ }^{\mathrm{d}}$ g_maluta@yahoo.com.br, USP, Brasil
}

\begin{abstract}
Resumo
0 texto discute maneiras de incentivar a atividade inovadora de engenharia de projeto de produto no setor automotivo, particularmente no segmento de autopeças. Utiliza instrumentos de pesquisa científica para fundamentar a sugestão de instrumentos de política pública. Trabalha dados secundários e realiza survey e entrevistas em profundidade, de cunho qualitativo. Baseia-se no conceito de sede de projeto desenvolvido por Salerno et al. (2009), que relaciona o controle das especificações de projeto (part numbers) com a escolha de fornecedores e, portanto, com o enraizamento da cadeia produtiva num determinado espaço nacional ou regional. lsso confere importância impar à atividade de projeto de produto e a define como alavancadora da produção no setor. Propõe a criação de centros de pesquisa pré-competitiva, centros de serviços de ferramentaria e programa massivo de extensão gerencial/organizacional para PMEs, com consultoria dentro das empresas, para aumentar sua capacitação e integrá-las em instrumentos públicos de incentivo à inovação.
\end{abstract}

Palavras-chave

Inovação. Indústria automobilística. Projeto de produto. Desenvolvimento industrial. Política de inovação.

\section{Introdução}

0 presente texto busca analisar e propor medidas de política pública para alavancar a atividade de engenharia de projeto de produto no setor automotivo, particularmente no segmento de autopeças. Análise geral baseada nas bases de dados nacionais e setoriais, e sobre a evolução da estrutura da indústria (hierarquização de fornecedores, co-design etc.), forma o pano de fundo para pesquisa de campo que visou captar necessidades, tendências e possibilidades de instrumentos para alavancar as atividades inovativas e de projeto de produto nas empresas. 0 conceito de sede de projeto desenvolvido por Salerno et al. (2009) relaciona o controle das especificações de projeto (part numbers) com a escolha de fornecedores e, portanto, com o enraizamento da cadeia produtiva num determinado espaço nacional ou regional. $\mathrm{Ou}$ seja, quem controla part numbers tem grande poder para escolher (e vetar) fornecedores. Os autores mostram que casos de projetos sediados no Brasil apresentam maior participação de fornecedores locais, tanto em projeto de produto quanto em produção. Assim, verifica-se uma relação direta entre atividades de projeto de produto no país, principalmente daqueles projetos cujo controle de gestão se encontra aqui, e o valor agregado no país na produção dos produtos. Isso confere importância ímpar à atividade de projeto de produto e a define como alavancadora da produção no setor. Parcialmente financiada pela Secretaria de Desenvolvimento Econômico do Estado deSão Paulo, a pesquisa foi construída a partir de entrevistas em profundidade com líderes empresariais (autopeças, montadoras) e governamentais, survey junto a 
sistemistas e entrevistas em profundidade com dirigentes de pesquisa e desenvolvimento (P\&D) de empresas com forte engenharia de produto no Brasil, bem como dirigentes de estamparias de médio porte fornecedoras de empresas de autopeças. 0 survey visou captar dados de empresas com forte P\&D, e as entrevistas procuraram aprofundar os aspectos nele detectados. As entrevistas com as estamparias foram feitas para que houvesse um contraponto, um grupo de controle de empresas que estão na cadeia automotiva, mas não apresentam atividades fortes e autônomas de P\&D ou projeto de produto.

0 setor automotivo tem sido objeto de muitos estudos e foco de variadas políticas públicas. Há várias razões para tanto. A indústria automotiva brasileira produziu 3,22 milhões de veículos em 2008 - pouco mais que em 2009, ano de retração desse segmento no mundo todo -, o que a levou à 6 a posição mundial, atrás de Japão, China, Estados Unidos, Alemanha e Coreia do Sul, e muito próximo desta última, que produziu 3,6 milhões no período. Vem apresentando crescimento absoluto e relativo ocupava a 7 a posição em 2007, atrás da França, tendo alcançado a $5^{\text {a }}$ posição entre os meses de janeiro e março de 2009 (INTERNATIONAL ORGANIZATION OF MOTOR VEHICLE MANUFACTURERS, 2009; ASSOCIAÇÃO NACIONAL DOS FABRICANTES DE VEÍCULOS AUTOMOTORES, 2009a).

Sua participação direta no produto interno bruto (PIB) brasileiro é de 5,5\%, e a Associação Nacional de Fabricantes de Veículos Automotores estima que, se considerados os impactos indiretos, a indústria automotiva representa 23\% do PIB, 1,53 milhão de empregos e relações com 200 mil empresas (incluindo relações indiretas), das quais 4.269 revendedores (ASSOCIAÇÃO NACIONAL DOS FABRICANTES DE VEÍCULOS AUTOMOTORES, 2009b). Sua cadeia produtiva é longa, relacionando-se com segmentos como o de vidro, borracha, siderurgia, alumínio, petróleo, petroquímica, química, álcool e biodiesel, bens de capital e outros, sem considerar setores ditos de serviços, como comércio, financiamento, seguros, oficinas, borracharias, assistência técnica, serviços técnicos especializados - engenharia, design, reciclagem etc.

Ademais, o setor é produtor e um dos principais consumidores e difusores - no sentido de "boas práticas" - de inovações tecnológicas e organizacionais. A mecânica de precisão tem relação direta com a produção de automóveis em alto volume, pois sem ela não haveria intercambialidade de peças, um dos princípios de Eli Whitney (BAGLEY, 2003) aplicados por Ford, fundamental para viabilizar esquemas de montagem sequenciados. Foi o lócus de difusão da linha de montagem (FLEURY; VARGAS, 1983), de aplicação das técnicas de tempos e movimentos, da diferenciação de produtos através de modelos anuais e da criação de famílias de veículos, da técnica de controle estatístico de qualidade - viabilizada pelo volume de produção, das ferramentas ditas japonesas de gestão da qualidade (HIRATA, 1993), como qualidade total, círculos de controle de qualidade, melhoria contínua, diversas modalidades de kaizen etc., das normas de qualidade ISO 9000 e sucedâneas, do esquema de plataforma como base para a diversificação de produtos, do just in time e seu aprofundamento (OHNO, 1997), o just in sequence, da modularidade e da segmentação da cadeia de fornecimento através de níveis de fornecedores/ tiering (SALERNO, 2001), da robótica, da pintura à base de água, e assim por diante.

Não se viabiliza indústria automotiva forte sem forte implantação de autopeças. 0 segmento de autopeças é responsável por um importante conjunto de inovações, seja autonomamente, seja em codesenvolvimento com montadoras, como é o caso de injeção eletrônica (substituindo o carburador), freios antiblocantes (ABS), air bags, eletronização das funções do veículo e computação de bordo, e inúmeros outros. Isso confere relevância e pertinência ao tema aqui em foco: a atividade de projeto de produto. Para o setor de autopeças, a inovação é fator decisivo para sua competitividade e crescimento. De acordo com a Pesquisa de lnovação Tecnológica na Indústria - Pintec (IBGE, 2005), esse setor registrou taxa de inovação da ordem de 45\% nos períodos 2001-2003 e 2003-2005, enquanto a taxa média da indústria brasileira atingiu, nos mesmos períodos, 33,5\%. A taxa de investimento em P\&D no setor sobre a receita líquida de vendas ficou em torno de 0,5\%, semelhante à média da indústria de transformação. Do total de pessoal empregado, 0,7\% são em P\&D, a mesma relação da indústria. Mas tal relação precisa ser entendida no âmbito da característica do segmento, que apresenta atividade fabril muito mais intensiva em mão de obra que outros setores. Tal é corroborado pelo índice muito superior, se comparado à média da indústria, da proporção de empresas que realizaram atividades internas de P\&D (com equipes próprias, portanto): 17,4\% no período 2001-2003, caindo para 11,4\% no período 2003-2005, para uma média de 6\% na indústria. Ou seja, é um setor particularmente relevante para estudo das atividades de inovação de produto em geral, e de projeto de produto em particular.

\section{Revisão bibliográfica}

A indústria automobilística viveu algumas fases distintas no país. Após sua implantação em maior escala, a partir dos anos 60, e do crescimento, nos 
anos 70 , passou por instabilidade nos anos 80 , até a recuperação devido aos acordos da Câmara Setorial e desdobramentos, como o Regime Automotivo (ARBIX; ZILBOVICIUS, 1997). Na segunda metade dos anos 90, a indústria automobilística mundial promoveu nova onda de internacionalização, investindo nos chamados mercados emergentes - leste europeu, China, América Latina. Naquela época, o Brasil absorveu parte significativa desses investimentos (LUNG et al., 1999; ZILBOVICIUS; MARX; SALERNO, 2002), e a indústria aqui localizada presenciou importantes mudanças estruturais, tornando-se um campo de experimentações com visibilidade mundial (LUNG et al., 1999; HUMPHREY; SALERNO; LECLER, 2000).

Em 1997, a Volkswagen inaugura uma fábrica e um conceito que se tornaria símbolo da nova organização da cadeia de valor automotiva, com a introdução da modularidade no fornecimento (e, em muitos casos, no projeto do módulo) e da hierarquização dos fornecedores em níveis ou tiers (MARX; ZILBOVICIUS; SALERNO, 1997), com o advento de empresas ditas modulistas ou sistemistas, que fornecem à montadora subconjuntos ou módulos inteiros, entregues muitas vezes diretamente no ponto exato da linha onde será montado: reduz-se, assim, o número de fornecedores diretos, com a criação de níveis hierárquicos ou tiers na cadeia de fornecimento. Salerno (2001) caracterizou o período como de criação de novas relações de fornecimento (modularidade) e de relocalização de atividades (condomínios industriais), de reestruturação das empresas, principalmente na produção, mas também atingindo áreas de projeto (CLARK; FUJIMOTO, 1991; DIAS, 2003; BECKER; ZIRPOLI, 2003; DIAS; SALERNO, 2009), de distribuição (GRANDE, 2004), além de incursões em atividades diversas de serviços (reparos, locação, serviços financeiros), conforme Leaver et al. (2004) e Muniz (2005); reorganização das atividades de projeto de produto, como a consolidação do co-design com fornecedores, a busca de centralização de projeto ("carro mundial") e seu fracasso, estratégia que foi substituída pela de plataformas mundiais e, depois, associada à de centros de competência ou de centros de projetos mundiais (DIAS; SALERNO, 2009). Camargo et al. (2007), em análise econométrica a partir das bases do IBGE, mostram que as autopeças, particularmente os sistemistas, tiveram melhor desempenho econômico do que as montadoras no período de consolidação do sistema modular (1996-2005), o que sugere que os sistemistas estejam mais robustos para investimentos em capacidade ou em P\&D.

0 processo de escolha de fornecedores em vigor é muito semelhante entre as diversas montadoras.
Lima (2004) e Salerno et al. (2003) mostram que os fatores qualificadores ao fornecimento são certificação de qualidade, capacidade financeira (para reduzir risco de descontinuidade de fornecimento dado que há poucos fornecedores por parte ou subconjunto, e para procurar garantir atualização tecnológica), qualificação do processo produtivo do fornecedor potencial (analisada pela engenharia e pela área de qualidade da montadora), capacidade de engenharia (adequação de software gráfico, prototipagem, capacidade de desenvolvimento de produto - fator decisivo para veículos cuja sede de projeto está localizada no Brasil), histórico de fornecimento. Preço é fator ganhador de pedidos (CERA; MAIA; ALVES FILHO, 2007; LIMA, 2004; SALERNO et al., 2003), ou seja, dado que certo número de fornecedores possui certificação de qualidade, capacidade financeira, capacidade de engenharia e bom histórico, eles são homologados como potenciais fornecedores, e aquele que apresentar melhor preço numa dada concorrência ganha o pedido.

Tanto Lima (2004) quanto Salerno et al. (2003) consideram que na escolha dos fornecedores participam, tipicamente, equipes de compras, qualidade, engenharia de produto, logística. Quando a função financeira é separada da de compras, ela também participa. Qualidade e engenharia têm papel decisivo na qualificação dos candidatos, uma vez que avaliam sua capacidade de produção e de desenvolvimento de produto, ou seja, sua capacidade de produzir conforme as especificações das montadoras e nos volumes requeridos.

Assim, a engenharia tem, na prática, poder de veto sobre candidatos ao fornecimento (SALERNO et al., 2009). Corroborando a literatura, levantamos casos de montadoras no Brasil em que a diretoria de compras propôs uma opção de fornecimento mais barata e a engenharia da montadora no centro matriz de $\mathrm{P} \& \mathrm{D}$ argumentou que a empresa não possuía condições técnicas de fornecimento, alegando incapacidade de produzir o ferramental necessário. Tal foi o caso com candidata ao fornecimento do painel (em plástico) de veículo topo de linha da montadora no país. Em outro caso, a engenharia da matriz vetou o fornecedor proposto pela subsidiária brasileira para um produto cuja sede de projeto estava na matriz, apesar desse fornecedor trabalhar com a subsidiária desde que ela se estabeleceu no Brasil.

Nessas condições, a engenharia da montadora passa a ser decisiva na escolha de fornecedores. 0 "leilão" de preços só ocorre após a engenharia aprovar os candidatos. Por decorrência, passa a ser decisiva a localização da engenharia, ou melhor, 
passa a ser decisiva a localização da unidade na qual se encontra a engenharia que analisa os candidatos ao fornecimento. Essa engenharia é aquela da unidade que é sede do projeto do veículo, isto é, a unidade que centraliza a gestão e as decisões sobre o projeto, seu desenvolvimento, suas modificações. 0 contato com fornecedores-chave acontece já na fase de definição do conceito do veículo. A unidade que desenvolve o projeto desde a fase de conceito (a fase inicial de um projeto de veículo, que define suas características gerais) é aquela que vai contatar os fornecedores, obtendo vantagem aqueles que estão localizados próximos à montadora. A proximidade não é física, mas sim de negócios, de relacionamento, de geração de valor de serviço (SALERNO, 2001).

A própria viabilidade de importação é menor quando o veículo tem sede de projeto no Brasil, pois nessa situação há peças e partes não projetadas e/ou produzidas no exterior, levando a que o desenvolvimento experimental das peças em si e delas no conjunto do carro seja mais facilmente feito no país. Ainda, a engenharia que habilita fornecedores é a engenharia local, que tem um cardápio de fornecedores diferente do da matriz, com empresas locais já conhecidas seja pelo histórico, seja pelo monitoramento do parque industrial local.

Assumiremos tais assertivas, uma vez que, nos procedimentos iniciais da pesquisa - entrevistas com dirigentes empresariais e discussão no evento com empresários, entes governamentais e especialistas do setor -, elas foram validadas. 0 conceito de sede de projeto, particularmente, tem grande força conceitual e prática. Ele parece óbvio quando revelado, mas se não explicitado passa despercebido. Ele separa analiticamente a engenharia em geral, as atividades de projeto, da organização estratégica, da divisão internacional do trabalho de projeto que ocorre no setor automotivo (DIAS, 2003). E qualifica essa forma de organização, uma vez que nem todas as atividades de engenharia têm o mesmo peso e significado.

No tocante à política pública, uma série de estudos discute sua eficiência no que tange à inovação em geral e ao estímulo aos gastos de P\&D nas empresas. Avellar (2008) mostra que incentivos fiscais induziram aumento dos gastos de $P \& D$ das empresas beneficiadas; De Negri e Salerno (2005) mostram que empresas que inovam e diferenciam produtos crescem mais, têm melhor inserção externa em mercados mais sofisticados; ainda, tudo o mais constante, uma empresa que diferencia e inova produto paga salário 23\% superior àquela que não diferencia. Araújo (2005) mostra que gastos de $P \& D$ de empresas estrangeiras no Brasil estimulam os investimentos e os gastos em P\&D das empresas nacionais, num efeito encadeador. Queiroz (2005) aponta uma janela de oportunidades para a atração de centros de P\&D de empresas transnacionais. Fleury, A. e Fleury, M. T. L. (2004) relacionam uma série de estudos que procuram demonstrar a oportunidade de política industrial baseada no tecido industrial e na inovação.

Ou seja, a literatura sugere que é relevante e pertinente discutir como alavancar inovação e diferenciação de produtos em geral, e no setor de autopeças em particular, dadas suas características discutidas acima.

\subsection{Metodologia e procedimentos adotados}

A pesquisa tem como objetivo conhecer melhor uma dada realidade e indicar meios para mudá-la, aproximando-se dos esquemas de pesquisa exploratória (YIN, 1994) e de pesquisa-ação (THIOLLENT, 1997). 0 tema, bastante ligado à gestão de operações em geral, ou, mais especificamente, à gestão estratégica da inovação, do ponto de vista das empresas, e à gestão de políticas públicas, do ponto de vista do Estado, é pertinente para ser estudado via surveye estudos qualitativos, conforme Yin (1994), Eisenhardt (1989) e Voss, Tsikriktsis e Frohlich (2002). Para a condução do levantamento de campo, utilizamos recomendações de Eisenhardt (1989), como as relativas ao número de casos (entrevistas com dirigentes de P\&D de sistemistas até a configuração de padrão) e aos esquemas de coleta e processamento de informações, e de Voss, Tsikriktsis e Frohlich (2002), conforme detalharemos abaixo. 0 Quadro 1 sintetiza os procedimentos realizados.

Baseamo-nos na análise de literatura pertinente, em análises a partir das bases de dados oficiais Rais - Relação Anual de Informações Sociais, Ministério do Trabalho e Emprego (BRASIL, 2007), Pintec - Pesquisa de Inovação Tecnológica na Indústria (INSTITUTO..., 2005), e em levantamentos com empresas, entidades empresariais, técnicos e eventos do setor. Realizamos inicialmente discussões estruturadas (via roteiro não diretivo) com a Diretoria Executiva e a Assessoria Econômica do Sindipeças (Sindicato Nacional da Indústria de Componentes para Veículos Automotores); Presidência e Diretoria Executiva da Anfavea (Associação Nacional dos Fabricantes de Veículos Automotores), para moldar as questões de estudo, verificar inicialmente sua pertinência e relevância, além de discutir o apoio operacional dessas entidades - facilitação de contatos etc. Posteriormente, realizamos entrevistas e levantamentos com a Presidência do Sindicato das 
Quadro 1. Técnicas e procedimentos de pesquisa.

1. Discussão com dirigentes governamentais e pesquisadores envolvidos com o tema de política industrial e de inovação.

- Análise bibliográfica sobre atividades de P\&D na cadeia automotiva e aprimoramento das questões/proposições para o estudo.

- Análise de dados secundários - publicações das entidades, bases de dados oficiais, imprensa especializada, participação em eventos do setor etc.

2. Elaboração da estratégia de pesquisa (survey + entrevistas quantitativas diversas).

3. Entrevistas iniciais com dirigentes do Sindipeças e da Anfavea para validação inicial das proposições (relação de P\&D com desenvolvimento do setor), da estratégia de pesquisa. Apoio para realização do levantamento - contatos, entrevistas, encaminhamento do survey.

4. Realização do survey, operacionalizado via Sindipeças.

5. Processamento e análise dos resultados do survey.

6. Entrevistas em profundidade com gestores de P\&D de sistemistas.

- Entrevistas com dirigentes de montadoras.

- Entrevistas com dirigentes de estamparias.

7. Validação das proposições com as entidades setoriais envolvidas (em evento geral e em discussões específicas).

8. Detalhamento das proposições - validação com técnicos especializados.

Fonte: elaborado pelos autores.

Empresas de Estamparia do Estado de São Paulo; diretores-empresários do núcleo de empresas que fornecem ao setor (tanto para montadoras como para autopeças) do mesmo sindicato. Paralelamente à realização das entrevistas descritas acima, participamos em evento organizado pela Secretaria de Desenvolvimento Econômico do Estado de São Paulo junto à Federação das Indústrias do Estado de São Paulo (Fiesp), envolvendo técnicos da secretaria, do Instituto de Pesquisas Tecnológicas (IPT), da Universidade de São Paulo (USP), da Fiesp e associações empresariais, no qual foram discutidas as premissas do projeto, como o conceito de sede de projeto, a centralidade da engenharia e do projeto de produto.

Com isso, validamos as ideias norteadoras do estudo e realizamos a coleta inicial de dados, que deu suporte à realização de um survey. Ele foi operacionalizado através de questionário fechado enviado às empresas do grupo "sistemista" afiliadas ao Sindipeças, em operação acertada em reunião com a Diretoria Executiva e a Assessoria Econômica do Sindipeças, que colaborou com a remessa e coleta dos questionários junto às firmas-alvo no segundo semestre de 2007, época de crescimento da demanda. Convênio entre a universidade e o Sindipeças possibilitou o recurso a sistema estruturado de coleta de informações junto às empresas, com contatos predefinidos, o que agilizou o levantamento, garantindo-lhe legitimidade, e assegurou a qualidade do survey, posto que os questionários chegaram às mãos certas. 0 alvo foram 40 empresas; 16 tiveram questionários considerados válidos após análise.

Os sistemistas são, tendencialmente, empresas maiores, com atividades estruturadas de projeto e desenvolvimento de produto, pois, conforme visto, isso é exigido pelas montadoras. Atendem, portanto, requisitos apontados por Voss, Tsikriktsis e Frohlich (2002) para seleção de amostra: são relevantes para o arcabouço conceitual e para as questões de pesquisa; apresentam possibilidade de que o fenômeno em estudo (P\&D, inovação) apareça; há factibilidade de realizar a pesquisa; não há problemas éticos envolvidos.

0 questionário, além da caracterização da empresa, continha cinco perguntas, abordando: gargalos físicos para P\&D - infraestrutura pública necessária para aumentar a quantidade e qualidade da atividade de P\&D (laboratórios, testes etc.); aspectos que atraem $\mathrm{P} \& \mathrm{D}$ para a empresa; tipo de auxílio público para ajudar nessa atração; utilização dos instrumentos de incentivo/fomento à P\&D na empresa; e necessidades de formação de profissionais. 0 survey foi complementado com entrevistas diretas, presenciais, com três sistemistas de porte, que projetam e desenvolvem produtos no Brasil e sediam aqui o desenvolvimento e lançamento de produtos inovadores em escala mundial, dois diretores de montadoras, dois empresários de estamparias que atuam na cadeia automotiva, técnicos especializados de centros de pesquisa públicos e gestores governamentais (federais e do Estado de São Paulo) da área de política industrial, tecnológica e de inovação. 
Além de sistemistas, o setor é composto por um grande conjunto de empresas de médio porte. Apesar de não serem elas as forças propulsoras de P,D\&l (pesquisa, desenvolvimento e inovação), muitas realizam tais atividades, principalmente de desenvolvimento de ferramental. Ferramental é particularmente bastante importante para estamparias e injetoras de plástico; tais ferramentas normalmente são caras, e definem a qualidade de conformação dos produtos. Ou seja, são empresas que têm atividade de engenharia, mas voltada a projeto de processo, pouco a projeto de produto. Isso nos levou a realizar levantamento com representantes e empresários do subsetor de estamparias, conforme mencionado acima, para captar reflexos na cadeia devido ao desenvolvimento de produtos pelas montadoras/autopeças, e para, simultaneamente, ter um grupo de controle com empresas com pouco projeto de produto. Isso também contribui para a triangulação, qual seja, o uso de diferentes métodos para estudar o mesmo fenômeno (YIN, 1994; VOSS; TSIKRITSIS; FROHLICH, 2002). Os temas discutidos foram os gargalos para desenvolvimento, confecção e certificação de estampos, assim como para integração eletrônica (via CAD) com os clientes (montadoras ou sistemistas). As análises iniciais de tais levantamentos foram validadas junto a dirigentes e especialistas do arranjo produtivo local (APL) do plástico do Grande $A B C$ e da Agência de Desenvolvimento do $A B C$, região que congrega 0 maior número relativo de empresas transformadoras de plástico. lsso porque partimos da hipótese, que foi confirmada, que há muitas similitudes entre os gargalos para desenvolvimento e confecção de estampos e de ferramental para injeção, por exemplo.

Os resultados da pesquisa foram validados tanto junto aos entrevistados (por contato presencial ou telefônico) quanto em evento coletivo, semelhante ao realizado no início do projeto, mas contando com um número maior de pessoas de empresas, inclusive de montadoras. As propostas por nós apresentadas nesse evento foram então refinadas conforme as críticas e sugestões.

\section{Resultados da pesquisa de campo}

0 survey, sintetizado nas Tabelas 1 a 7 , mostra dados interessantes. As empresas respondentes são de grande porte (Tabela 1), com estrutura formal de P\&D (Tabela 2), o que as qualifica para responder às questões foco da pesquisa, que são: os instrumentos de política pública para alavancar a atividade de projeto de produto no país que, conforme visto na revisão bibliográfica, impulsiona o setor e a economia como um todo. Como no setor a inovação tem forte correlação com o tamanho da empresa (DE NEGRI; SALERNO, 2005), nossa amostra parece ser adequada.

Ao contrário do discurso de algumas entidades empresariais (Confederação Nacional da Indústria - CNI, Associação Nacional de Pesquisa e Desenvolvimento das Empresas lnovadoras - ANPEl, Fiesp, por exemplo), as empresas pesquisadas revelam conhecer e utilizar os instrumentos recentes de incentivo à P\&D (Tabela 5). 0 fato de ninguém ter assinalado financiamento Fapesp, mesmo a maioria dos respondentes tendo sede no estado de São Paulo, indica que a questão foi respondida com critério, uma vez que a Fapesp não efetua financiamento para esse público - o item serviu para controle metodológico e análise de distorções, como recomendado pela literatura sobre metodologia

Tabela 1. Pessoal ocupado nas empresas pesquisadas.

\begin{tabular}{cc}
\hline Pessoal ocupado & No de empresas \\
\hline Até 499 pessoas ocupadas & 5 \\
De 500 a 999 pessoas ocupadas & 2 \\
Acima de 1.000 pessoas ocupadas & 8 \\
Sem informação & 1 \\
\hline
\end{tabular}

Fonte: questionários elaborados pelos autores.

Tabela 2. Pessoal ocupado em Pesquisa \& Desenvolvimento.

\begin{tabular}{cc}
\hline Pessoal ocupado em P\&D & No de empresas \\
\hline Até 9 pessoas ocupadas & 8 \\
De 10 a 29 pessoas ocupadas & 5 \\
Acima de 30 pessoas ocupadas & 2 \\
Sem informação & 1 \\
\hline
\end{tabular}

Fonte: questionários elaborados pelos autores.

Tabela 3. Gargalos físicos para Pesquisa \& Desenvolvimento.

\begin{tabular}{cc}
\hline $\begin{array}{c}\text { Principais gargalos físicos para } \\
\text { atividades de P\&D }\end{array}$ & No de empresas \\
\hline $\begin{array}{l}\text { Laboratórios para pesquisas e/ou testes } \\
\text { Equipamentos modernos para pesquisas, } \\
\text { análises estruturais, simulações virtuais etc. } \\
\text { Mão de obra qualificada }\end{array}$ & 8 \\
\hline Fonte: questionários elaborados pelos autores. & 3 \\
\hline
\end{tabular}

Tabela 4. Infraestrutura para Pesquisa \& Desenvolvimento.

\begin{tabular}{cc}
\hline $\begin{array}{c}\text { Infraestrutura necessária para } \\
\text { aumentar investimentos em P\&D }\end{array}$ & No de empresas \\
\hline Acesso a laboratórios públicos & 5 \\
(universidades) & 5 \\
Laboratórios para testes & 4 \\
Centros de referência (como IPT) & 2 \\
Nenhum & \\
\hline
\end{tabular}

Fonte: questionários elaborados pelos autores. 
Tabela 5. Instrumentos de incentivo público à P\&D utilizados.

\begin{tabular}{ll}
\hline $\begin{array}{c}\text { Instrumentos de apoio } \\
\text { público utilizados }\end{array}$ & No de empresas \\
\hline $\begin{array}{c}\text { Incentivos fiscais para P\&D (lei do bem) } \\
\text { Financiamento BNDES indireto } \\
\text { (via banco comercial) }\end{array}$ & 6 \\
$\quad \begin{array}{l}\text { Financiamento BNDES direto } \\
\text { Contratos com universidades com as } \\
\text { facilidades da lei de inovação }\end{array}$ & 1 \\
$\begin{array}{c}\text { Subvenção econômica para custeio de } \\
\text { desenvolvimento de produtos inovadores } \\
\text { (lei de inovação) }\end{array}$ & 1 \\
$\begin{array}{c}\text { Subsídio para fixação de mestres e } \\
\text { doutores na empresa (lei do bem) } \\
\text { Financiamento Finep }\end{array}$ & 1 \\
Financiamento Fapesp & 2 \\
Bolsa para pesquisador (CNPq, Fapesp) & 0 \\
Recursos próprios & 1 \\
Outros** & 2 \\
\hline Fonte: questionários elaborados pelos autores. *Em andamento quando
\end{tabular}

do levantamento. ${ }^{* *}$ Treinamento de funcionários na matriz da empresa.

Tabela 6. Iniciativas do governo que poderiam atrair P\&D.

\begin{tabular}{cc}
\hline $\begin{array}{c}\text { Iniciativas do governo que } \\
\text { poderiam atrair P\&D }\end{array}$ & No de empresas \\
\hline $\begin{array}{c}\text { Redução de impostos diversos } \\
\text { (ICMS, PIS, Cofins etc.) } \\
\begin{array}{c}\text { Redução de impostos sobre } \\
\text { atividades de P\&D }\end{array}\end{array}$ & 5 \\
$\begin{array}{c}\text { Aumento das linhas de financiamento } \\
\text { às empresas }\end{array}$ & 4 \\
Aumento dos investimentos em \\
formação e qualificação de mão de obra \\
Melhoria da infraestrutura \\
(rodoviária, portuária)
\end{tabular}

Tabela 7. Demanda por engenheiros.

\begin{tabular}{cc}
\hline Engenheiros mais demandados & No de empresas \\
\hline Todas as especialidades & 4 \\
Mecânico & 4 \\
Produção & 4 \\
Materiais & 4 \\
Eletrônico & 4 \\
Mecatrônico & 3 \\
Químico & 3 \\
Metalúrgico & 1 \\
\hline
\end{tabular}

Fonte: questionários elaborados pelos autores.

(THIOLLENT, 1981). Já o discurso da Tabela 6 revela o senso comum - críticas a impostos, por exemplo. Mas mostra também uma demanda por financiamento e formação da força de trabalho.
As empresas apontaram gargalo no mercado de trabalho para engenheiros (Tabela 7). Esta é uma consideração geral: a economia crescia, o setor se ampliava a taxas muito superiores à geral, e tinha/ tem dificuldades no recrutamento. Dois gerentes de P\&D entrevistados, em empresas diferentes, cunharam frases similares: "engenheiros há; faltam bons engenheiros", que eles associam aos formados em determinadas escolas, a maioria públicas. Assim, os esforços recentes do Ministério da Educação (MEC) em priorizar a expansão dos cursos de engenharia nas universidades federais são louváveis, mas estão aquém do necessário.

0 panorama mostrado até aqui - empresas de porte, inovadoras, com estrutura formal de P\&D, que utilizam os novos instrumentos públicos de apoio e têm gargalos de mão de obra em engenharia - forma o pano de fundo para análise das Tabelas 3 e 4. Elas, em consonância com a literatura (AVELLAR, 2008; LONGO; OLIVEIRA, 2000), sugerem que as empresas aumentariam suas atividades de $\mathrm{P} \& \mathrm{D} /$ desenvolvimento de produto caso contassem com centros de pesquisa pré-competitivos, públicos, que pudessem, via contratos, prestarem-lhes serviços como testes, desenvolvimento, pesquisa pré-competitiva em geral. Por pesquisa pré-competitiva entendemos:

[...] aquela cujo resultado fornece conhecimentos para o estágio pré-comercial do produto ou são de emprego genérico para a melhoria de produtos existentes. Essa característica é que permite que o desenvolvimento da tecnologia se dê de maneira cooperativa, inclusive podendo ter como participantes e cofinanciadores empresas competidoras ou rivais [...] (LONGO; OLIVEIRA, 2000, p. 133).

Executivos de $P \& D$ entrevistados nas três empresas, técnicos do setor e dirigentes do Sindipeças e da Anfavea consideraram muito oportuna tal possibilidade. Os executivos das sistemistas utilizam-se de centros no exterior quando não os encontram aqui. Mas para casos inéditos, cuja liderança de P\&D está sediada no Brasil, pode não haver centros de pesquisa adequados no exterior. Este é o caso de laboratórios para análise de processos de combustão e emissões voltados para biocombustíveis, particularmente para o etanol. Não há instalações onde se possa examinar a formação do gotejamento do álcool na câmara de combustão conforme o formato do bico injetor e da câmara, por exemplo. Isso permitiria um conjunto de inovações para aumento de eficiência de motores, redução do consumo e de emissões. 0 tema motorização a álcool/emissões foi unanimemente sugerido como prioridade nos workshops e nas entrevistas realizados. De certa 
forma, tal prioridade lastreia-se nos acúmulos (ou recursos) do setor no Brasil, tendo respaldo na visão baseada em recursos (PROENÇA, 1999; FLEURY, A.; FLEURY, M. T. L., 2003). Interessante é notar que tal proposição não é formulada pelas entidades empresariais gerais, talvez por lhes faltar distanciamento dos diversos interesses; por outro lado, não lhes é antagônica (ASSOCIAÇÃO NACIONAL DE PESQUISA E DESENVOLVIMENTO DAS EMPRESAS INOVADORAS, 2004).

\subsection{Levantamentos junto a pequenas e médias empresas do subsetor estamparia}

Como o survey e entrevistas com dirigentes de P\&D foram direcionados para o grupo sistemista, composto por empresas de médio-grande porte, realizamos, conforme justificado acima, levantamento em profundidade com dirigentes empresariais e empresários de empresas de pequeno-médio porte do segmento de estamparia.

0 panorama nesse segmento é bastante diferente. Não há demanda, efetiva ou potencial, para apoio à pesquisa pré-competitiva como há entre os sistemistas. As questões relevantes aqui são o desenvolvimento, a fabricação e a certificação de ferramental. Este pode apresentar custos elevados (de até centenas de milhares de reais), e impacta diretamente na qualidade das peças produzidas. Ainda, as montadoras e sistemistas demandam interação com seus sistemas $C A D$, o que pode significar que um fornecedor de médio porte tenha que possuir tantas estações e softwares de CAD quantos sejam os utilizados pelos clientes efetivos e potenciais. Evidentemente, isso limita possibilidades de expansão dessas empresas.

0 desenvolvimento, e principalmente a fabricação de estampos (e, por semelhança, de ferramental para injeção de plástico), para que seja alcançado o padrão do setor, exigem investimento em capital fixo de monta: sistemas CAD/CAM/CAE, máquinas de eletroerosão, centros de usinagem, equipamentos/fornos de tratamento térmico. Todos os empresários e técnicos entrevistados foram unânimes no diagnóstico, que também foi compartilhado pelos entrevistados sistemistas, e validado nos eventos realizados.

Outro ponto levantado nas entrevistas foi o extensionismo gerencial e tecnológico focado nas empresas de menor porte. Tal extensionismo teria como característica o diagnóstico da empresa realizado feito por equipe/consultor (que podem ser de universidades, por exemplo) que a visita e a analisa in loco, discutindo com os gestores o diagnóstico e proposições de melhoria. 0 esquema de diagnóstico e proposições associadas guarda paralelo com diagnósticos semelhantes e ações desenvolvidas em vários países, mas ainda pouco estruturadas no Brasil (ARBIX et al., 2007). A constatação é que programas de extensionismo normalmente têm como instrumentos cursos, realizados principalmente fora da empresa. Apesar de algumas tentativas recentes para outros setores (como o Programa de Extensão Industrial Exportadora - Peiex, do Ministério do Desenvolvimento, Indústria e Comércio Exterior, introduzido em 2003, hoje sob gestão da Agência Brasileira de Promoção de Exportações e Investimentos - Apex Brasil, e programas da Agência Brasileira de Desenvolvimento Industrial - ABDI), há poucos programas através dos quais se realiza análise dentro da empresa, por meio de consultoria específica.

0 paralelo mais difundido, extinto há décadas, foi o sistema de crédito rural. Sua obtenção, junto ao Banco do Brasil, estava condicionada à elaboração de um projeto técnico pela Emater local. 0 financiamento abrangia também a realização do projeto, o que orientava produtores rurais e lhes trazia novas tecnologias, novas perspectivas de cultivares etc.

\section{Conclusões e recomendações}

0 setor automobilístico brasileiro apresenta condições especiais. Os dados apresentados no início do texto mostram que seu peso econômico é forte, envolve milhares de empreendimentos e milhões de empregos direta e indiretamente. Possui atividades relevantes de pesquisa, desenvolvimento e inovação no país. A literatura mostra - e os entrevistados concordam - que há forte relação entre a localização de atividades de projeto de produto e de produção física: sediar projetos, controlar as especificações de engenharia, influi diretamente no processo de escolha de fornecedores.

A partir desse quadro, foram realizados survey e entrevistas em profundidade que possibilitassem discutir políticas públicas de apoio à atividade de pesquisa e desenvolvimento (P\&D) e inovação de produto no setor automobilístico. Os levantamentos realizados, por meio de instrumentos diversos, nos permitem tecer conclusões e recomendações para o aumento das atividades de pesquisa, desenvolvimento, engenharia e inovação em geral no setor. Os desafios podem ser caracterizados como: a) aumentar o investimento; b) mudar a qualidade do investimento futuro; c) consolidar, ampliando qualitativa e quantitativamente, a engenharia de 
produto no Brasil, principalmente de produtos cuja engenharia é sediada no Brasil.

Com isso, pode-se fazer frente a duas ameaças: enfrentar a concorrência de países do leste europeu e asiáticos em projeto de produto, e enfrentar a concorrência dos produtores chineses e indianos em produtos de entrada no mercado, ponto forte da indústria radicada no Brasil.

A indústria automobilística como um todo - incluindo, portanto, o segmento de autopeças - é uma indústria pouco "local", ou seja, fluxos de capital, de conhecimento (projetos, patentes etc.) e de produtos em processo ou acabados, viajam o mundo, dependendo apenas de restrições regulatórias (como barreiras tarifárias ou de outra ordem) ou de decisões das próprias companhias. As montadoras dividem os mercados entre suas filiais, e os produtos fabricados no Brasil apresentam, até o momento, limitada inserção nos mercados dos países centrais.

A última onda forte de investimentos no setor montadoras e autopeças - ocorreu no final dos anos 90, quando o Brasil liderou a recepção de IDE no setor, e foi palco de mudança estrutural na cadeia de fornecimento, com o fornecimento modular e o tiering.

\subsection{Recomendações de políticas}

0 desenvolvimento da pesquisa propiciou a elaboração das proposições abaixo, que foram validadas junto a parte das empresas entrevistadas e por entidades empresariais setoriais concernentes - Sindipeças, Anfavea, Sindicato das Estamparias, e junto a entidades e personalidades reunidas nos eventos citados anteriormente. As proposições são:

a) Implementação de centros específicos focados na pesquisa pré-competitiva e em apoio laboratorial de base para uso compartilhado pelas empresas interessadas, podendo focar até num estágio mais sofisticado (materiais, nanotecnologia, eletrônica embarcada). Tal centro pode nuclear centros, laboratórios, universidades e competências públicas e privadas já existentes, como por exemplo, as design houses de chips oriundas do projeto $\mathrm{Cl}$-Brasil do Ministério da Ciência e Tecnologia, já em atividade. As empresas interessadas contratariam o centro para pesquisa, desenvolvimento, testes e assemelhados, alavancando suas atividades de P\&D sem incorrer em investimentos (imobilizado, capital fixo) ou em gastos com mão-de-obra especializada, que podem ter baixa ocupação, inviabilizando-se do ponto de vista privado isolado (empresas independentes). Como prioridade levantada, emissões e motores, ligada ao tema cada vez mais relevante das restrições ambientais, ao mesmo tempo em que abrange competências desenvolvidas no Brasil (motores a etanol, injeção multicombustível), massa crítica empresarial e de competência em pesquisa e em órgãos reguladores (Conselho Nacional de Trânsito - Contran; Companhia de Tecnologia de Saneamento Ambiental Cetesb e assemelhados em outros estados). Surpreendentemente, é área que carece de centro laboratorial atualizado. Numa pré-especificação feita com especialistas entrevistados (das empresas pesquisadas, do IPT e de universidades, estes contatatos por telefone), tal laboratório constaria de prédio (edificação) com isolamento acústico, utilidades (água, ar, área para armazenamento e dutos de combustíveis etc.), equipamentos para análise de emissões para a próxima geração de motores, com frenagem, sistemas para análise de nebulização de álcool (sistema laser para medida da gota - o álcool, conforme a temperatura, forma gotas muito grandes, que aderem na parede da câmara de combustão, atrapalhando o rendimento e a queima), nariz calibrador etc.

b) Estruturas públicas de apoio ao projeto, desenvolvimento e teste de ferramental para apoiar empresas de menor porte. 0 ferramental é o coração de atividades de estamparia e transformação plástica, entre outras; o desenvolvimento de ferramental para o setor automotivo pode atingir cifras importantes, de centenas de milhares de reais, tornando-se um entrave ao crescimento de pequenas empresas. Ainda, países como Espanha e Portugal aproveitaram fundos de desenvolvimento da União Europeia para o estabelecimento, via subsídios, de centros de ferramental. A China vem crescendo nessa área. A lógica desse tipo de estrutura é a de oferecer serviços; é diferente da lógica do centro referenciado acima, mais voltados para pesquisa pré-competitiva, mais perto da ciência, digamos assim. Levantamos três alternativas para localização de tais estruturas: i) junto a institutos de pesquisa tipo IPT (SP), Instituto Nacional de Tecnologia - INT (RJ), Centro Tecnológico - Cetec (MG) etc.; ii) como centro autônomo; iii) junto a escolas de formação técnica, por exemplo, ligadas a um Centro Federal de Educação Tecnológica - IFSP, ao Centro Paula Sousa (SP) etc. Essa última alternativa nos parece a mais promissora, pois aproveita melhor os recursos e alavanca a formação técnica, um dos gargalos da indústria, uma vez que os equipamentos podem servir simultaneamente à formação e à prestação de serviços, e a atividade didática pode ser mesclada com a profissional. É uma alternativa mais conservadora, do ponto de vista da demanda, do que a alternativa centro autônomo, mas, se a demanda for muito alta, centros autônomos poderiam vir a ser criados. 0 fundamental é que 
a escola técnica (ou o centro autônomo ou o instituto de pesquisa) tenha capacidade de realizar contratos com presteza, como uma empresa.

c) Programa massivo de extensão gerencial e tecnológica, através de consultoria realizada dentro das empresas de menor porte. Essa consultoria teria como papel essencial levantar problemas e sugerir ações de cunho organizacional/gerencial para as empresas atendidas, antes de focar na troca de equipamentos, adequação de produtos etc., isto é, antes de consultoria tecnológica estrito senso. Ainda, a consultoria tem o papel de difundir instrumentos públicos de apoio ao tipo de empreendimento em questão. Ou seja, ao invés de ser um programa que tem uma solução à procura de um problema, seria um programa para levantar problemas, apontando alternativas de solução. A consultoria pode ser realizada conveniadamente com universidades e faculdades localizadas nas diversas regiões, ganhando agilidade, capilaridade e sem que o programa constitua grandes estruturas.

Relativamente aos gargalos de mão-de-obra, não há muitas alternativas. Trata-se de investir em programas de formação técnica de qualidade, aumentar as vagas de engenharia nas universidades públicas, para suprir as carências do presente e do futuro. É geral, nas empresas entrevistadas, a observação da carência de engenheiros com boa qualificação, que os entrevistados associam a determinadas escolas; há engenheiros no mercado; faltam os de boa formação.

As propostas acima relacionadas foram diretamente baseadas na pesquisa realizada. A utilização de procedimentos baseados em métodos científicos pode ajudar em muito nas elaborações mais diversas, seja nas empresas, seja no setor público. No presente caso, o foco foram políticas públicas de apoio à pesquisa, desenvolvimento e engenharia num setor importante da economia brasileira.

\section{Referências}

ARAÚJO, R. D. Esforços tecnológicos de firmas transnacionais e domésticas. In: DE NEGRI, J. A.; SALERNO, M. S. (Orgs.) Inovações, padrões tecnológicos e desempenho das firmas industriais brasileiras. Brasília: IPEA, 2005. cap. 4, p. 119-170.

ARBIX, G. et al. Projeto Metodologia para Conceber e Executar Plano de Mobilização Brasileira pela Inovação Tecnológica MOBIT. Relatório Final. São Paulo: ABDI/Cebrap/Observatório da Inovação e Competitividade da USP, 2007. Disponível em: <http://www.observatoriodainovacao.org.br>.

ARBIX, G.; ZILBOVICIUS, M. (Orgs.). De JK a FHC: a reinvenção dos carros. São Paulo: Scritta, 1997.

ASSOCIAÇÃO NACIONAL DE PESQUISA E DESENVOLVIMENTO DAS EMPRESAS INOVADORAS - ANPEl. Como alavancar a inovação tecnológica nas empresas. São Paulo, 2004.
ASSOCIAÇÃO NACIONAL DOS FABRICANTES DE VEÍCULOS AUTOMOTORES - ANFAVEA. Carta da ANFAVEA, n. 283. São Paulo: ANFAVEA, 2009a.

ASSOCIAÇÃO NACIONAL DOS FABRICANTES DE VEÍCULOS AUTOMOTORES -ANFAVEA. Anuário Estatístico da Indústria Automobilística Brasileira 2009. São Paulo: ANFAVEA, 2009b. Disponivel em: <http://www.anfavea. org.br>.

AVEllaR, A. P. Avaliação de impacto do Programa de Desenvolvimento Tecnológico Industrial (PDTI) sobre o gasto em atividades inovativas e em P\&D das empresas Industriais. In: KUBOTA, L. C.; DE NEGRI, J. A. (Orgs.). Políticas de incentivo à inovação tecnológica no Brasil. Brasília: Ipea, 2008.

BAGLEY, K. The early American Industrial Revolution, 1793 1850. Mankato: Bridgestone Books, 2003.

BECKER, M.; ZIRPOLl, F. Organizing new product development - knowledge hollowing-out and knowledge integration the Fiat Auto case. International Journal of Operations and Production Management, v. 23, n. 9, 2003.

BRASIL. Ministério do Trabalho e Emprego. RAIS. Relação Anual de Informações Sociais. Brasília, DF, 2007. Disponivel em: <http://www.mte.gov.br>.

CAMARGO, 0. S. et al. Modularity and profits: a study of assemblers and suppliers profits after ten years of tiering in Brazil. In: GERPISA INTERNATIONAL COLLOQUIUM, 15., 2007, Paris. Anais... Disponível em: <http://www.gerpisa. univ-evry.fr>.

CERA, A. L.; MAIA, J. L.; ALVES FILHO, A. G. Aspectos estratégicos, estruturais e relacionais de três cadeias de suprimentos automotivas. Gestão \& Produção, v. 14, n. 2, p. 253-265, 2007.

CLARK, K. B.; FUJIMOTO, T. Product development performance: strategy, organisation and management in the world auto industry. Boston: Harvard Business Press, 1991.

DE NEGRI, J. A.; SALERNO, M. S. (Orgs.) Inovações, padrões tecnológicos e desempenho das firmas industriais brasileiras. Brasília: IPEA, 2005. Disponível em: <http:// www.ipea.gov.br>.

DIAS, A. V. C. D. Produto mundial, engenharia brasileira: integração de subsidiárias no desenvolvimento de produtos globais na indústria automobilística. 2003. Tese (Doutorado em Engenharia de Produção) - Universidade de São Paulo, São Paulo, 2003. Disponível em: <http://www.usp.br>.

DIAS, A. V. C. D.; SALERNO, M. S. Descentralização das atividades de Pesquisa, Desenvolvimento e Engenharia de empresas transnacionais: uma investigação a partir da perspectiva de subsidiárias automotivas. Gestão \& Produção, v. 16, n. 2, p. 187-199, 2009.

EISENHARDT, K. M. Building theories form case studies research. The Academy of Management Review, v. 14, n. 5, p. 532-554, 1989.

FLEURY, A.; FLEURY, M. T. L. Estratégias competitivas e competências essenciais: perspectivas para a internacionalização da indústria no Brasil. Gestão \& Produção, v. 10, n. 2, p. 129-144, 2003.

FlEURY, A.; FlEURY, M. T. L. Política Industrial 2. São Paulo: Publifolha, 2004. (Coleção Biblioteca Valor).

FLEURY, A.; VARGAS, N. (Eds). Organização do trabalho: uma abordagem interdisciplinar. São Paulo: Atlas, 1983.

GRANDE, M. M. Distribuição de veículos: uma análise da reestruturação dos canais de distribuição de automóveis novos no Brasil. 2004. Tese (Doutorado em Engenharia da Produção) - Escola Politécnica, Universidade de São Paulo, São Paulo, 2004. Disponível em: <http://www.usp.br>. 
HIRATA, H. (Org.). Sobre o “modelo" japonês: automatização, novas formas de organização e de relações de trabalho. São Paulo: EDUSP, 1993.

HUMPHREY, J.; SALERNO, M. S.; LECLER, Y. (Eds.). Global strategies and local realities: the auto industry in emerging markets. London: MacMillan, 2000.

INSTITUTO BRASILEIRO DE GEOGRAFIA E ESTATÍSTICA - IBGE. Pesquisa Industrial de Inovação Tecnológica 2003. Rio de Janeiro, 2005.

INTERNATIONAL ORGANIZATION OF MOTOR VEHICLE MANUFACTURERS - OICA. Production Statistics. Paris, 2008. Disponivel em: <http://oica.net/category/productionstatistics>. Acesso em: 26 abr. 2010.

LEAVER, A. et al. Adding finance to industrial companies: the cases of Caterpillar, Ford and GE. In: GERPISA INTERNATIONAL COLLOQUIUM, 12., 2004, Paris. Disponível em: <http://www.gerpisa.univ-evry.fr>.

LIMA, J. C. S. Um Estudo sobre a reconfiguração da função compras em empresas do setor automotivo. 2004. Tese (Doutorado em Engenharia de Produção) - Escola Politécnica, Universidade de São Paulo, São Paulo, 2004. Disponivel em: <http://www.usp.br>.

LONGO, W. P.; OLIVEIRA, A. R. P. Pesquisa cooperativa e centros de excelência. Parcerias Estratégicas, n. 9, p. 129-144, 2000. Disponivel em: <http://cgee.org.br>.

LUNG, Y. et al. Flexibility through modularity: experimentations with fractal production in Brazil and in Europe. In: LUNG, Y. et al. (Eds.) Coping with variety. flexible productive systems for product variety in the auto industry. Aldershot: Ashgate, 1999. cap. 9, p. 224-257.

MARX, R.; ZILBOVICIUS, M.; SALERNO, M. S. The "modular consortium" in a new VW truck plant in Brazil: new forms of assembler and suppliers relationship. Integrated Manufacturing Systems - The International Journal of Manufacturing Technology Management, v. 8, n. 5, p. 292-8, 1997.

MUNIZ, S. T. G. What is the role of services in the automotive industry? In: GERPISA INTERNATIONAL COLLOQUIUM,
13., 2005, Paris. Anais... Disponível em: <http://www. gerpisa.univ-evry.fr>.

OHNO, T. O Sistema Toyota de Produção: além da produção em larga escala. Porto Alegre: Bookman, 1997.

PROENÇA, A. Dinâmica estratégica sob uma perspectiva analítica: refinando o entendimento gerencial. Arché, v. 8, n. 23, p. 95-134, 1999.

QUEIROZ, S. R. R. Globalização da P\&D: oportunidades para o Brasil. Parcerias Estratégicas, n. 20, 2005. Disponível em: $<$ http://cgee.org.br>.

SALERNO, M. S. et al. A nova configuração da cadeia de fornecimento na indústria automobilística no Brasil. Revista de Administração, v. 38, n. 3, p. 192-204, 2003.

SALERNO, M. S. et al. Design headquarters and modular supply best practices in the automobile industry: lessons learned from the Brazilian case. International Journal of Manufacturing Technology Management, v. 18, n. 4, p. 361-376, 2009.

SALERNO, M. S. The characteristics and the role of modularity in the automotive business. International Journal of Automotive Technology and Management, v. 1, n. 1, p. 92-107, 2001.

THIOLLENT, M. A captação de informações nos dispositivos de pesquisa social: problemas de distorção e relevância. Cadernos CERU, n. 16, p. 81-105, 1981.

THIOLlENT, M. Pesquisa-ação nas organizações. São Paulo: Atlas, 1997.

VOSS, C.; TSIKRIKTSIS, N.; FROHLICH, M. Case research in operations management. International Journal of Operations and Production Management, v. 22, n. 2, p. 195-219, 2002

YIN, R. K. Case study research: design and methods. 2. ed. Thousand Oaks: Sage, 1994.

ZILBOVICIUS, M.; MARX, R.; SALERNO, M. S. A comprehensive study of the transformation of the Brazilian automotive industry. International Journal of Automotive Technology and Management, v. 2, n. 1, p. 10-23, 2002.

\title{
Leveraging research, development and innovation in the Brazilian autoparts industry
}

\begin{abstract}
The paper discusses how to leverage product design activities in the automotive sector, with focus on the components industry. Scientific research methods are used to anchor public policy suggestions. It is based on the concept of design headquarters (SALERNO et al., 2009), that relates design specifications and part numbers control with the power to choose suppliers - with local or national supply chain roots. It gives upmost importance to product design activity, which may be considered as an inductor of local production. The paper proposes the creation of precompetitive research centers, service centers for tool and die design, and a massive extension of the organizational/managerial program, with experts/consultants visiting plants to suggest improvements and to integrate companies with public agencies tasked with promoting innovation.
\end{abstract}

Keywords

Innovation. Automotive industry. Product design and development. Industrial development. Innovation policy. 